\title{
Assessment of Ceramic Water Filters for the Removal of Bacterial, Chemical, and Viral Contaminants
}

\author{
P. M. Nigay ${ }^{1}$; A. A. Salifu²; J. D. Obayemi ${ }^{3}$; C. E. White ${ }^{4}$; A. Nzihou ${ }^{5}$; and W. O. Soboyejo ${ }^{6}$
}

\begin{abstract}
In this study, a comprehensive assessment of doped ceramic water filters (doping with hydroxyapatite and alumina) was conducted for potential application in household water treatment. The efficiency/reliability was assessed via statistical data analysis and normal distributions. It was found that the doped ceramic water filters had high porosity $(63.25 \% \pm 0.31 \%$ by volume $)$ and a substantial flow rate $\left(14.76 \pm 1.43 \mathrm{~L} \cdot \mathrm{h}^{-1}\right)$. The removal of bacterial contaminants [i.e., log reduction value (LRV)] was also found to be associated with the percentage of porosity. Hence, the doped filters were both efficient and reliable in removing bacterial contaminants (LRV of 4.69 \pm 0.19 ). The removal of chemical/viral contaminants was related to the doping with hydroxyapatite and alumina. Due to kinetics, the removal of viral contaminants also depended on the flow rate of the doped ceramic water filters. This resulted in high efficiency in the removal of viral contaminants (LRV of $3.47 \pm 0.35$ ) and high reliability in the removal of chemical contaminants (LRV of $2.26 \pm 0.07$ ). The current results suggest that the doped filters are suitable materials for application in household water treatment.
\end{abstract}

Author keywords: Bacteria; Ceramic water filters; Chemicals; Household water treatment; Viruses.

\section{Introduction}

Upon request of the Inter-American Development Bank, a study was conducted to determine the most appropriate technology for water filtration in South America (ICAITI 1984). The study compared several factors: availability; ease of manufacture, operation, and distribution; bacterial efficiency; and the final cost of 10 filters. The only models that met the criteria consisted of clay filters (Lantagne 2001a, b). They were produced by mixing clay with sawdust and water. Typically, the mixtures were molded in the form of pots and sintered by firing at approximately $900^{\circ} \mathrm{C}$ (Donachy 2011). The porous structure resulting from the thermal degradation of the sawdust generated a path for water to flow through the fired clay via gravity. The fired filters were placed in plastic receptacles with faucets through which filtered water could be collected.

Mass production started in 1999 after Hurricane Mitch hit Central America and caused damage to the potable water supply

${ }^{1}$ Postdoctoral Researcher, Dept. of Mechanical Engineering, Worcester Polytechnic Institute, Worcester, MA 01609 (corresponding author). ORCID: https://orcid.org/0000-0003-2204-6205. Email: pmnigay@mines -albi.fr

${ }^{2}$ Assistant Research Professor, Dept. of Biology and Biotechnology, Worcester Polytechnic Institute, Worcester, MA 01609. Email: aasalifu@ wpi.edu

${ }^{3}$ Assistant Research Professor, Dept. of Biology and Biotechnology, Worcester Polytechnic Institute, Worcester, MA 01609. Email: jdobayemi@ wpi.edu

${ }^{4}$ Assistant Professor, Dept. of Civil and Environmental Engineering, Princeton Univ., Princeton, NJ 08544. ORCID: https://orcid.org/0000 -0002-4800-7960. Email: whitece@ princeton.edu

${ }^{5}$ Professor, Centre RAPSODEE, Mines Albi, Campus Jarlard, Route de Teillet, 81013 Albi Cedex 09, France. Email: ange.nzihou@mines-albi.fr

${ }^{6}$ Provost, Dept. of Mechanical Engineering, Worcester Polytechnic Institute, Worcester, MA 01609. Email: wsoboyejo@wpi.edu

Note. This manuscript was submitted on April 23, 2019; approved on February 10, 2020; published online on May 8, 2020. Discussion period open until October 8, 2020; separate discussions must be submitted for individual papers. This paper is part of the Journal of Environmental Engineering, (C) ASCE, ISSN 0733-9372. for millions of people (USAID 1998). A ceramic water filter production workshop was established in Nicaragua by Potters for Peace, a US-based nonprofit organization. Through the efforts of the workshop, more than 5,000 filters were produced and distributed to the people in less than 6 months (Potters for Peace 2019). These efforts also resulted in standardization of production with the use of hydraulic presses and aluminum molds. Potters for Peace extended this model around the world, training people on the production of ceramic water filters with local resources. The organization contributed to the establishment of ceramic water filter production workshops in over 20 countries including Bolivia, Cambodia, Haiti, and Nigeria (Clasen et al. 2004; Sobsey et al. 2008; Bielefeldt et al. 2009; Annan et al. 2015).

Originally, the ceramic water filters were made for the removal of bacterial contaminants (e.g., E. coli) from drinking water. Bacteria were removed as they became trapped in the nano- and micropores of the filters (Oyanedel-Craver and Smith 2008). The literature indicates that original filters have a removal efficiency of $99.9206 \%$ for bacterial contaminants (van der Laan et al. 2014). Some studies have shown that chemical contaminants (e.g., heavy metals and pesticides) can also be removed from water by doping the ceramic filters with hydroxyapatite (Yakub and Soboyejo 2013). The doped filters remove up to $93.7200 \%$ of the chemical contaminants. Typically, the contaminants are removed by substitution for elements of the hydroxyapatite in the clay matrix (Bhatnagar et al. 2011). Recent studies have shown that doping ceramic water filters with metal oxides can also lead to $97.4881 \%$ removal of viral contaminants from drinking water (Brown and Sobsey 2009; Michen et al. 2012; Nigay et al. 2019). The removal is achieved by adsorption of the viral contaminants on iron, aluminum, or magnesium oxides that are kept unchanged in the clay matrix.

The development of ceramic water filters for the concurrent removal of bacterial, chemical, and viral contaminants from drinking water was a significant step forward in regard to the primary purpose (ICAITI 1984). These filters contribute to the decline of many water-borne diseases such as diarrhea, skeletal/dental fluorosis, poliomyelitis, etc. Nevertheless, the performance of such filters must be suitable for water to be safe to drink. Thus, a comprehensive 
assessment of the doped filters must be carried out before they can be used for household water treatment. The novelty of this work was to conduct a statistical analysis of the parameters affecting performance of the filters including percentage of porosity, flow rate, log reduction values (LRVs) for bacterial/chemical/viral contaminants, and mechanical performance. The distribution of the results was investigated using a normal distribution analysis approach. This means that both the level and probability of contamination can be predicted. Finally, the implications of this study will be discussed for application in household water treatment.

\section{Materials and Methods}

\section{Raw Materials}

The clay that was used in this study was redart clay, a commercial product obtained from Cedar Heights (Resco Products, Pittsburgh, Pennsylvania). Furthermore, the additives that were used with the clay consisted of sawdust, hydroxyapatite, and alumina. The sawdust (oak/pine mixture) came from JB Sawmill \& Landclearing Inc. (Hopkinton, Massachusetts). It was subjected to a 500- $\mu \mathrm{m}$ sieving. On the other hand, hydroxyapatite (PRAYPHOS TCP 108 FG, Prayon, Engis, Belgium) and alumina (Brockmann I, Sigma-Aldrich, St. Louis, Missouri) were used as obtained from the suppliers. They consisted of a white powder (average particle size of $5 \mu \mathrm{m}$ ) of $\mathrm{Ca}_{3}\left(\mathrm{PO}_{4}\right)_{2}$ and a white powder (average particle size of $100 \mu \mathrm{m}$ ) of $\mathrm{Al}_{2} \mathrm{O}_{3}$, respectively.

\section{Processing of the Ceramic Water Filters}

The ceramic water filters were made from a mixture of clay, sawdust, hydroxyapatite, and alumina. The sawdust was used as a poreforming agent to trap some contaminants, while hydroxyapatite and alumina were used for the substitution and adsorption of contaminants, respectively (see Introduction).

The mixture was prepared in a planetary mixer (MX20, Avantco Equipment, Lancaster, Pennsylvania) with addition of water until a paste was formed. The proportions of the mixture were as follows: clay, $45 \%$ by weight; sawdust, $15 \%$ by weight; hydroxyapatite, $20 \%$ by weight; and alumina, $20 \%$ by weight (i.e., $30 \%$ by volume of clay, $50 \%$ by volume of sawdust, $10 \%$ by volume of hydroxyapatite, and $10 \%$ by volume of alumina). These proportions were regarded as optimum for filtration and mechanical performance based on the results of the authors' previous research (Nigay et al. 2018, 2019).

The resulting paste was compression-molded in a hydraulic press (TRD55002, Torin, Ontario, California) with a two-piece (upper/lower) aluminum mold. The frustum-shape filters were obtained using a pressure of $20 \mathrm{t}$. They had an internal base diameter of $210 \mathrm{~mm}$, internal lid diameter of $300 \mathrm{~mm}$, and internal height of $240 \mathrm{~mm}$, with a thickness of $15 \mathrm{~mm}$ for the base and $10 \mathrm{~mm}$ for the sides. After pressing, the frustum-shaped filters were air-dried for 5 days and fired in an electrical kiln (Dragon24, Paragon, Mesquite, Texas). The firing was carried out from $30^{\circ} \mathrm{C}$ to $500^{\circ} \mathrm{C}$ using a ramp of $50^{\circ} \mathrm{C} / \mathrm{h}$, and from $500^{\circ} \mathrm{C}$ to $950^{\circ} \mathrm{C}$ using a ramp of $100^{\circ} \mathrm{C} / \mathrm{h}$ with a holding time of $3 \mathrm{~h}$ at $950^{\circ} \mathrm{C}$.

\section{Characterization of the Structure}

The porosity of the filters was measured via water absorption. The measurements were performed using fired samples with dimensions of $30 \times 30 \times 5 \mathrm{~mm}^{3}$. The samples were introduced in a plastic desiccator and subjected to a vacuum pressure (30 kPa for $4 \mathrm{~h}$ ). This was followed by partial $(2 \mathrm{~h})$ and full $(24 \mathrm{~h})$ immersion of the samples into water. Atmospheric pressure was restored in the plastic desiccator. The samples were kept under full immersion for an additional $24 \mathrm{~h}$. Finally, the mass of the samples was measured under water (i.e., hydrostatic weighing), in air after wet-wiping and in air after drying at a temperature of $105^{\circ} \mathrm{C}$ for $24 \mathrm{~h}$

$$
\varepsilon=\frac{m_{w}-m_{d}}{m_{w}-m_{h}}
$$

The porosity was obtained from Eq. (1), where $m_{h}=$ hydrostatic mass; $m_{w}=$ wet mass; and $m_{d}=$ dry mass.

\section{Determination of Hydraulic Performance}

The hydraulic performance of the samples was determined by water discharge. Typically, a $10 \mathrm{~L}$ plastic bucket was placed under the ceramic water filters. The mass of water discharged from the filters to the plastic bucket was recorded as a function of time using a PGL 20001 balance (Adam Equipment, Oxford, Connecticut) that was connected to a computer with Adam Equipment DU software. The water discharge was then obtained by dividing the mass of water discharged by the density $\left(1 \mathrm{~g} \cdot \mathrm{cm}^{-3}\right)$. Finally, the flow rate was regarded as equal to the slope of the water discharge as a function of time.

\section{Determination of Filtration Performance}

The efficiency of the filters was tested for bacteria, chemicals, and viruses. The tests were conducted using $E$. coli (bacteria), fluoride (chemical), and MS2 (virus) as model contaminants (suspensions/ solutions). These contaminants are widely used in the field of household water treatment. This means that the filtration performance of the filters from this study can be compared to a great number of results from the literature. The contaminants were tested separately. Replicate tests were also performed in the same filters with no cleaning/sterilization, to simulate household water treatment.

The concentration of the aqueous suspensions/solutions of contaminants was measured prior to filtration and after filtration. This was done using $10 \mathrm{~L}$ of water (i.e., maximum amount). The efficiency was estimated from Eq. (2), where LRV $=\log$ reduction value; $C_{P F}=$ concentration prior to filtration; and $C_{A F}=$ concentration after filtration

$$
\mathrm{LRV}=-\log _{10}\left(\frac{C_{A F}}{C_{P F}}\right)
$$

E. coli C-3000 strain (ATCC 15597) was grown in Escherichia medium (ATCC Medium 271). The growth was carried out at $37^{\circ} \mathrm{C}$ for $24 \mathrm{~h}$ in a G25 incubator (New Brunswick Scientific, Enfield, Connecticut). The suspensions were produced by introducing $10 \mathrm{~mL}$ of the phase culture into $10 \mathrm{~L}$ of deionized water. They were poured in the filters in colony-forming units of $10^{6.26}$ viable cells (cfu/ $\left.\mathrm{mL}^{-1}\right)$. The measurements were conducted with $E$. coli count plates (Petrifilm, 3M, St. Paul, Minnesota) after incubation at $37^{\circ} \mathrm{C}$ for $24 \mathrm{~h}$. It was regarded as sufficient to collect $10^{1}$ viable cells after filtration.

The aqueous solutions of fluoride (10 L) were prepared by dissolution of sodium fluoride (ACS reagent, $>99 \%$, from SigmaAldrich) in deionized water. They had a concentration of 1,000 ppm, which was regarded as the minimum value to collect aqueous solutions above the detection limit (i.e., 1 ppb) after filtration. The concentration of the aqueous solutions was measured by ion chromatography using an ICS-2100 instrument (Dionex, Sunnyvale, California).

MS2 (ATCC 15597B1) was grown using the broth propagation technique. The growth was conducted in a growing culture 
(6-h old) of E. coli C-3000 strain (ATCC 15597). After propagation, it was purified by centrifugation and transferred into $10 \mathrm{~L}$ of deionized water. The resulting suspensions had a concentration of plaque-forming units of $10^{5.28} \mathrm{PFU} \cdot \mathrm{mL}^{-1}$. It was enough to collect $10^{1}$ viable cells after the filtration process in the filters. The enumeration was conducted using the double agar overlay plaque assay (Kropinski et al. 2009).

\section{Determination of Mechanical Performance}

Mechanical performance was measured via three-point bending tests (Instron 8548 microtester, Norwood, Massachusetts). The specimens were prepared from the top section (considering bottom, middle, and top sections) using a wet-tile saw. They had dimensions of $60 \times 10 \times 5 \mathrm{~mm}^{3}$. The tests were conducted with a load cell of $500 \mathrm{~N}$ and a load span of $50 \mathrm{~mm}$ using a ramp of $1 \mathrm{~mm} / \mathrm{min}$. The mechanical strength of the filters, $\sigma$, was calculated from Eq. (3), where $F_{\max }=$ maximum force; $\mathrm{L}=$ loading span; $\mathrm{B}=$ breadth; and $\mathrm{H}=$ height (ASTM 2017)

$$
\sigma=\frac{3 F_{\max } \mathrm{L}}{2 \mathrm{BH}^{2}}
$$

The fracture toughness was determined using single edge notch bend (SENB) specimens with dimensions of $60 \times 10 \times 5 \mathrm{~mm}^{3}$ and notches of $2 \mathrm{~mm}$ (length-to-width ratio of $0.40-0.45$ ). They were tested in the same machine (Instron 8548 microtester) with a same ramp of $1 \mathrm{~mm} / \mathrm{min}$

$$
K_{I c}=f\left(\frac{a}{W}\right) \times \sigma_{f} \times \sqrt{\pi a}
$$

The stress intensity factor $\left(K_{I c}\right)$ was estimated from Eq. (4), where $\sigma_{f}=$ stress at the peak load; $a=$ crack length; and $f(a / W)=$ compliance function (ASTM 2012).

\section{Statistical Data Analysis}

The experimental results of the porosity, flow rate, LRVs (bacterial, chemical, and viral contaminants) and mechanical properties were processed by statistical data analysis. This analysis was conducted using the results of 20 tests. The distribution of the values was then represented with a normal distribution. The probability density functions were obtained from Eq. (5), where $x$ is the variable; $\bar{x}$ is the average value; and $\sigma$ is the standard deviation (Dixon and Massey 1951)

$$
F(x)=\frac{1}{\sqrt{2 \pi \sigma^{2}}} e^{-\frac{(x-\bar{x})^{2}}{2 \sigma^{2}}}
$$

The fit between the experimental results and the normal distributions was tested using the Kolmogorov-Smirnov test for normality. It was quantified by the $p$-values (limit for statistical significance of 0.05 ), which are the probability of having normally distributed results. Normally distributed results mean that the probability of a certain occurrence can be predicted.

\section{Results and Discussion}

\section{Structure of the Ceramic Water Filters}

Fig. 1 presents the distribution of the percentage of porosity obtained after firing the ceramic water filters with hydroxyapatite and alumina at $950^{\circ} \mathrm{C}$. The results show that the porosity is equal to $63.25 \% \pm 0.31 \%$ by volume. This value represents a combination

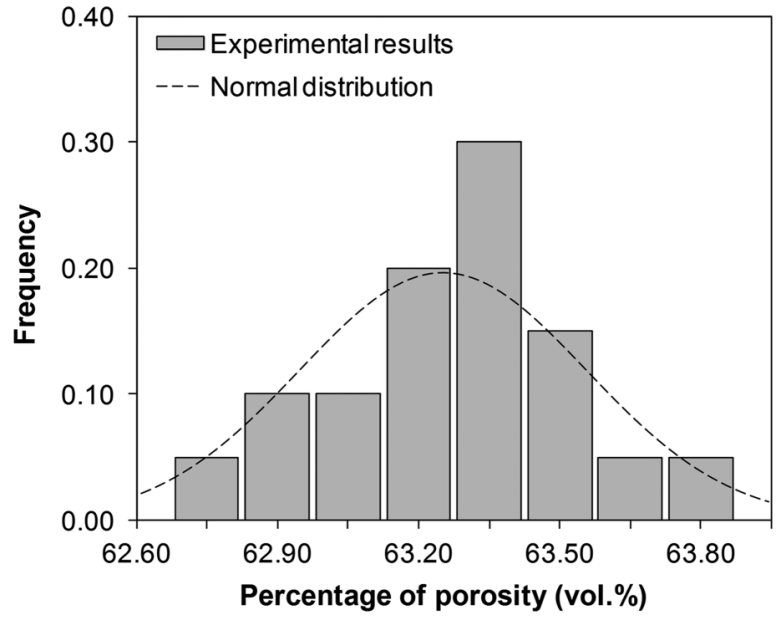

Fig. 1. Distribution of the percentage of porosity of the ceramic water filters with $20 \%$ by weight incorporation of hydroxyapatite and $20 \%$ by weight incorporation of alumina. Data were obtained using water absorption analysis.

between the microscopic pores resulting from the process (pressing, drying, and combustion of the sawdust during firing) and the nanopores resulting from the doping of the filters. It can be noted that the standard deviation $(0.31 \%$ by volume $)$ is relatively low. Typically, the values are all included between $62.75 \%$ and $63.80 \%$ by volume because the pores are homogeneous and well dispersed in the clay matrix (Nigay et al. 2019). This can be attributed to the sieving of the sawdust prior to the mixing with the clay and the additives. Finally, it can be observed that the porosity of the filters is well represented by the normal distribution (i.e., $p$-value of 0.76$)$.

\section{Hydraulic Performance of the Ceramic Water Filters}

Fig. 2 shows the distribution of the flow rate obtained after firing the ceramic water filters at $950^{\circ} \mathrm{C}$. The flow rate of the filters is equal to $14.76 \pm 1.43 \mathrm{~L} \cdot \mathrm{h}^{-1}$. This value is relatively high compared with the values from the literature, which usually range from 1.3 to $2 \mathrm{~L} \cdot \mathrm{h}^{-1}$ (Yakub et al. 2013). This is attributed to the doping

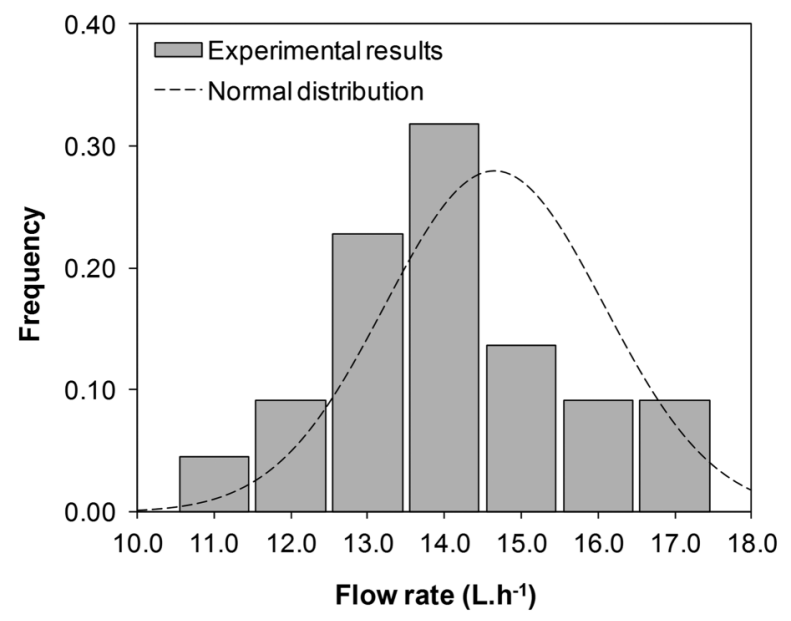

Fig. 2. Distribution of the flow rate of the ceramic water filters with $20 \%$ by weight incorporation of hydroxyapatite and $20 \%$ by weight incorporation of alumina. Data were obtained using water discharge. 


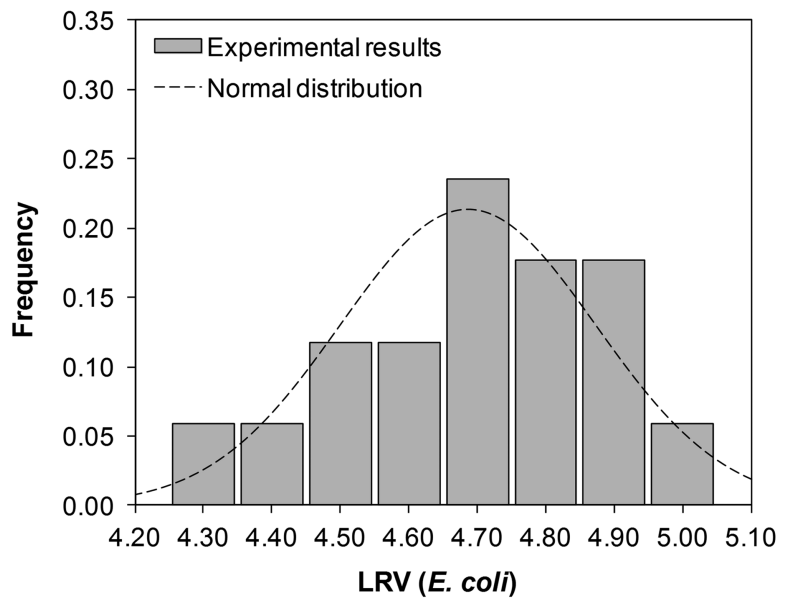

Fig. 3. Distribution of the LRV for E. coli of the ceramic water filters with $20 \%$ by weight incorporation of hydroxyapatite and $20 \%$ by weight incorporation of alumina. Data were obtained using count plate enumeration.

of the filters with hydroxyapatite and alumina, which results in a high percentage of porosity and a high permeability (Nigay et al. 2019). On the other hand, the standard deviation is relatively important. The values of the flow rate range from 11.0 to $17.0 \mathrm{~L} \cdot \mathrm{h}^{-1}$. Such a wide distribution cannot be explained by the porosity (Fig. 1), which has a relatively narrow distribution $(63.25 \% \pm$ $0.31 \%$ by volume). In fact, the variability is attributed to the moisture of the ceramic water filters. If the filters are not completely soaked when water is introduced, some adsorption occur before water starts flowing. This means that a lower volume of water would remain in the filters, resulting in lower pressure applied on the base and in a lower flow rate. Nevertheless, the values of the flow rate are normally distributed (i.e., $p$-value of 0.65 ). The distribution confirms that the content of the ceramic water filters $(10 \mathrm{~L})$ is discharged in approximately $4 \mathrm{~h}$. Thus, such filters can purify up to $60 \mathrm{~L}$ of water a day.

\section{Filtration Performance of the Ceramic Water Filters}

The LRV for bacterial contaminants (i.e., E. coli) is presented in Fig. 3. The results show that the doped filters have an LRV of $4.69 \pm 0.19$ (removal efficiency of $99.9979 \% \pm 0.0011 \%$ ). The value is higher than those observed in the literature for conventional filters (i.e., LRV of 4.00) (Brown and Sobsey 2010; van Halem 2006). This is attributed to the high percentage of porosity in which the bacterial contaminants are trapped (Yakub and Soboyejo 2012). The results also show that the distribution of the LRV for bacterial contaminants (i.e., standard deviation) is relatively narrow, varying from 4.30 (removal efficiency of $99.9950 \%$ ) to 5.00 (removal efficiency of $99.9968 \%$ ). The narrow distribution of the LRV corresponds with the narrow distribution of the porosity values, in contrast to the wide distribution of the flow rate. This suggests that the extent of the LRV for bacterial contaminant is related to the percentage of porosity. On the other hand, the flow rate of the ceramic water filters has no significant effect on the removal of bacterial contaminants. The distribution of the LRV is well represented by the normal distribution (i.e., $p$-value of 0.95). It confirms that the doped filters are both efficient and reliable in removing bacterial contaminants. Typically, the doped filters remove $99.9957 \%$ of the bacterial contaminants with a certainty of $95 \%$.

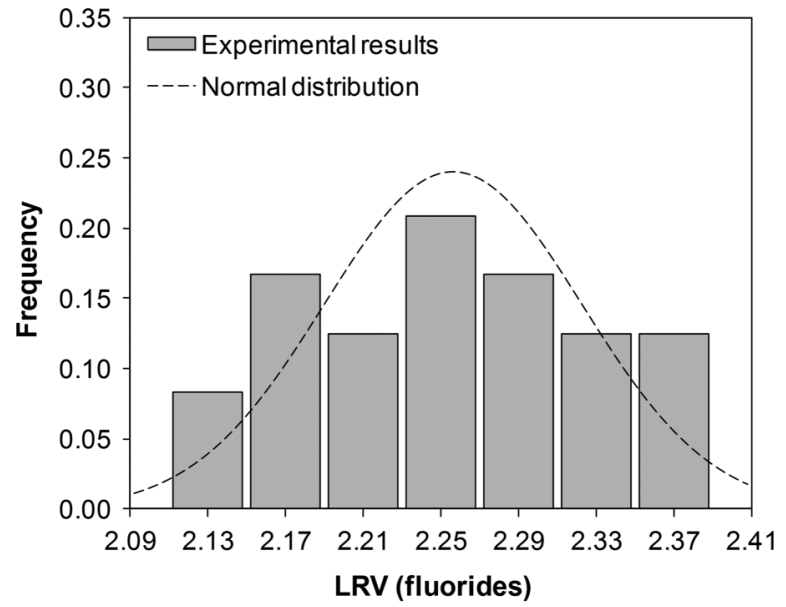

Fig. 4. Distribution of the LRV for fluoride of the ceramic water filters with $20 \%$ by weight incorporation of hydroxyapatite and $20 \%$ by weight incorporation of alumina. Data were obtained using ion chromatography.

The LRV for chemical contaminants (i.e., fluoride) is presented in Fig. 4. It can be observed that the doped ceramic water filters have an LRV of $2.26 \pm 0.07$ (removal efficiency of $99.4458 \% \pm 0.0916 \%$ ). This means that the doped filters are not as efficient in removing chemical contaminants as they are in removing bacterial contaminants (removal efficiency of $99.9979 \% \pm 0.0011 \%$ for $E$. coli). This is attributed to the capture mechanism. According to the literature, chemical contaminants are removed from water via substitution for elements of the hydroxyapatite in the fired clay matrix (de Leeuw 2002). The results show that the distribution of the LRV is much narrower for chemical contaminants than for bacterial contaminants. The values range from 2.13 (removal efficiency of $99.2587 \%$ ) to 2.37 (removal efficiency of $99.5734 \%$ ). This suggests that the LRV for chemical contaminants does not depend on the porosity or the flow rate for which the distribution of the values is broad. In fact, the removal of chemical contaminants from drinking water is controlled by the substitution mechanism - the kinetics of the substitution mechanism are much faster than the flow rate of the ceramic water filters, even though it can be high for doped filters. It can be observed that the values of the LRV for chemical contaminants are normally distributed (i.e., $p$-value of 0.94). Hence, the probability of contamination is minimized by the low standard deviation. This makes the doped filters more reliable/suitable for the removal of chemical contaminants, despite limited efficiency. They remove $99.2734 \%$ of the chemical contaminants from water with a certainty of $95 \%$.

Fig. 5 shows the LRV of the ceramic water filters for viral contaminants (i.e., MS2). The LRV is equal to $3.47 \pm 0.35$ (removal efficiency of $99.9661 \% \pm 0.0429 \%$ ). This value is comparable with those obtained for bacterial and chemical contaminants (LRVs of $4.69 \pm 0.19$ and $2.26 \pm 0.07$, respectively). Nevertheless, the distribution of the values (standard deviation) is much wider. The values of LRV for viral contaminants range from 2.80 (removal efficiency of $99.8415 \%$ ) to 4.00 (removal efficiency of $99.9900 \%$ ). Such a wide distribution is comparable with that of the flow rate (Fig. 2). The literature has reported that viral contaminants are removed from drinking water via surface adsorption on the alumina (Michen et al. 2013; Tsao et al. 2016); however, these results suggest that the removal of viral contaminants is also related to the flow rate of the ceramic water filters. This may be due to the fact that the doping of the ceramic water filters results in a significant 


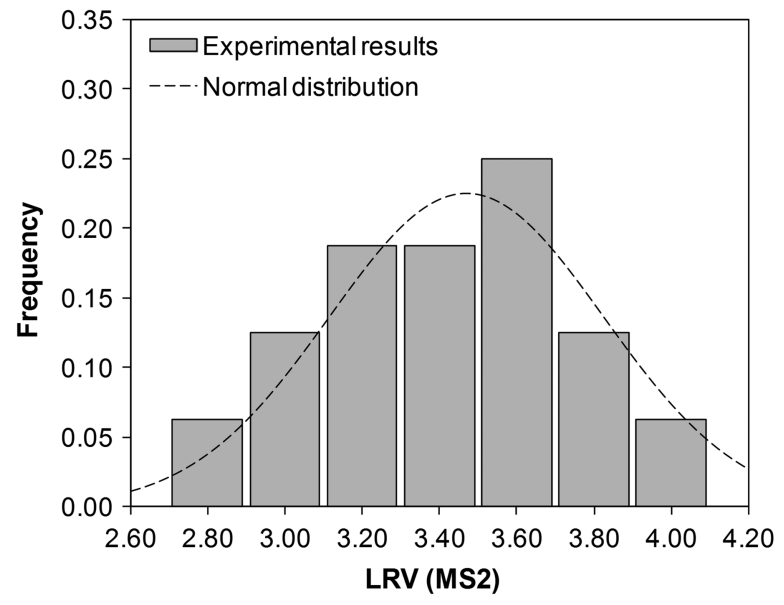

Fig. 5. Distribution of the LRV for MS2 of the ceramic water filters with $20 \%$ by weight incorporation of hydroxyapatite and $20 \%$ by weight incorporation of alumina. Data were obtained using double agar overlay plaque assay.

increase in the flow rate (Nigay et al. 2019). Typically, the water flow through the clay matrix becomes too fast to fulfill the kinetics of surface adsorption on alumina. It can also be observed that the distribution of the LRV for viral contaminants is well represented by the normal distribution (i.e., $p$-value of 0.96). The efficiency of the filters makes them suitable for the removal of viral contaminants from drinking water, despite a wider range of LRVs. On average, such filters remove $99.8600 \%$ of the viral contaminants from drinking water with a certainty of $95 \%$.

\section{Mechanical Performance of the Ceramic Water Filters}

Fig. 6 presents the distribution of the mechanical strength obtained after firing of the doped ceramic water filters at $950^{\circ} \mathrm{C}$. It is seen that the doped filters have a mechanical strength of $0.88 \pm$ $0.07 \mathrm{MPa}$. This value is slightly lower than the mechanical strength for doped filters reported in the literature, which ranges from 3 to $4 \mathrm{MPa}$ (Yakub et al. 2012). This can be attributed to the high percentage of porosity (Fig. 1) with microscopic pores acting as

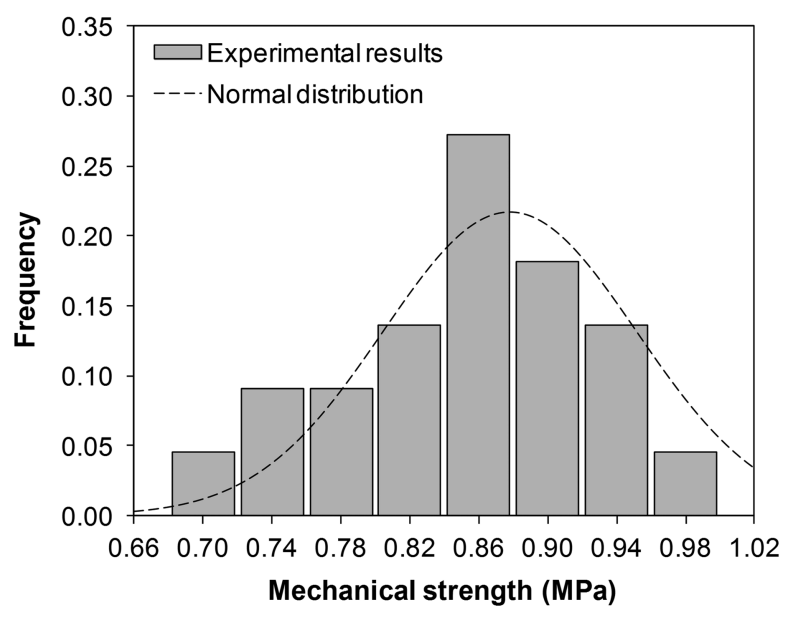

Fig. 6. Distribution of the mechanical strength of the ceramic water filters with $20 \%$ by weight incorporation of hydroxyapatite and $20 \%$ by weight incorporation of alumina. Data were obtained using three-point bending test.

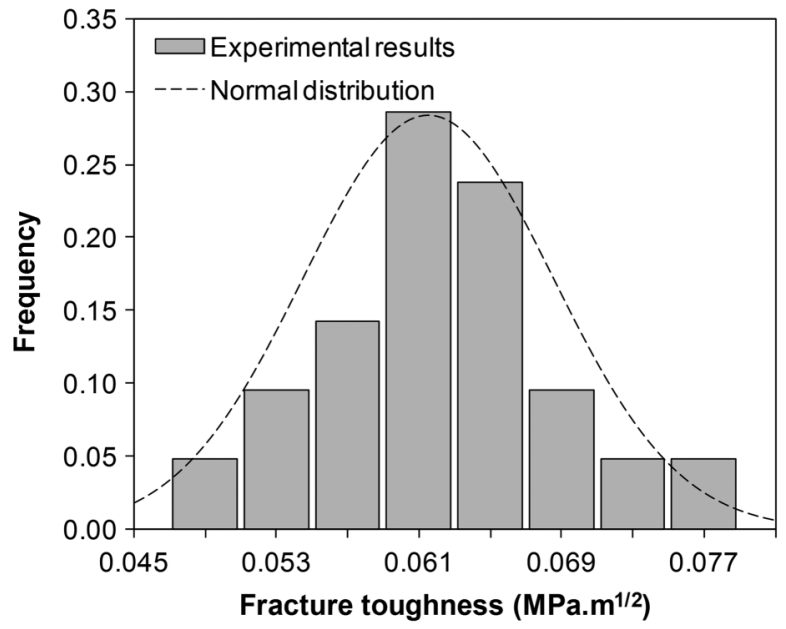

Fig. 7. Distribution of the fracture toughness of the ceramic water filters with $20 \%$ by weight incorporation of hydroxyapatite and $20 \%$ by weight incorporation of alumina. Data were obtained using three-point bending test.

defects (Nigay et al. 2017b). The hydroxyapatite and alumina that are embedded in the clay matrix (without any interaction with the clay) can also be considered as a source of fracture. Nevertheless, evidence from the filtration experiments shows that the mechanical strength is high enough for application in household water treatment. The doped filters were filled multiple times with the maximum amount of water $(10 \mathrm{~L})$ without undergoing any failure. Furthermore, the mechanical strength of the filters can be regarded as reliable, with a small variability in the results $(0.70$ to $0.98 \mathrm{MPa})$. This is attributed to the homogeneity of the pores and dispersion of the additives in the clay matrix, resulting from sieving the sawdust and doping with small particles (Nigay et al. 2017a).

Fig. 7 shows the distribution of the fracture toughness obtained after firing the doped ceramic water filters at $950^{\circ} \mathrm{C}$. The fracture toughness is equal to $0.061 \pm 0.007 \mathrm{MPa} \cdot \mathrm{m}^{1 / 2}$. As for mechanical strength, the value is lower than those (i.e., $0.35-0.37 \mathrm{MPa} \cdot \mathrm{m}^{1 / 2}$ ) from the literature (Plappally et al. 2011), because mechanical strength and fracture toughness are related to the structure of the ceramic water filters. The high percentage of porosity and of the additives, hydroxyapatite and alumina, results in slightly low mechanical properties. However, the homogeneity of the pores and the dispersion of the additives in the fired clay matrix make them reliable. It can be observed that the mechanical properties are normally distributed (i.e., $p$-value of 0.99 ). This means that the probability of fracture can be predicted. Overall, the doped filters are suitable for such an application in household water treatment.

\section{Implications}

This research shows that the doped ceramic water filters are suitable for application in household water treatment. They are more difficult to process than the nondoped filters (lower plasticity of the mixture); however, they are efficient and reliable for removing bacterial as well as chemical and viral contaminants. The use of doped ceramic water filters not only contributes to the decline of waterborne diseases like infectious diarrhea, but also helps reduce skeletal/dental fluorosis and poliomyelitis. It is important to note that the doped filters have a greater productivity than the nondoped filters. They can purify up to $60 \mathrm{~L}$ of water/day while the nondoped filters can only purify $10 \mathrm{~L}$ water/day. Furthermore, the doped filters can be produced at a relatively low cost (extra cost 
of USD1.10 using commercially available resources). The only limitation might be that real-world filter production would require a larger number of resources.

\section{Conclusions}

This work comprehensively assessed ceramic water filters doped with hydroxyapatite and alumina for potential application in household water treatment. Conclusions are summarized below.

1. The percentage of porosity and the flow rate of the doped ceramic water filters were relatively high. The variability of the results was small for porosity due to the preliminary sieving of the sawdust. However, the results were fairly variable for the flow rate due to a difference in the moisture content of the filters.

2. The filtration of bacterial contaminants (e.g., E. coli) was related to the percentage of porosity, while that of chemical (e.g., fluoride) and viral (e.g., MS2) contaminants was related to the doping with hydroxyapatite and alumina, respectively. Removal of viral contaminants also depended on the flow rate of the filters.

3. The doped ceramic water filters were efficient and reliable in the filtration of bacterial contaminants (LRV of $4.69 \pm 0.19$ ). The filtration of viral contaminants was also regarded as efficient despite a lower reliability (LRV of $3.47 \pm 0.35$ ). On the other hand, their reliability made the doped filters suitable for the filtration of chemical contaminants (LRV of $2.26 \pm 0.07$ ).

4. The statistical analysis showed that the experimental values of the study were normally distributed. The level and the probability of contamination were predicted for bacterial, chemical, and viral contaminants. The predictions confirmed that the doped ceramic water filters are suitable for application in household water treatment.

\section{Data Availability Statement}

Some or all data, models, or code generated or used during the study are available from the corresponding author by request (experimental results and statistical data analyses).

\section{Acknowledgments}

The authors acknowledge the Department of Mechanical Engineering, the Department of Biology and Biotechnology, and the Department of Civil and Environmental Engineering at WPI. The authors also acknowledge the RAPSODEE Research Center at Mines Albi, the Department of Mechanical and Aerospace Engineering, the Department of Civil and Environmental Engineering, and the Andlinger Center for Energy and the Environment at Princeton University.

\section{References}

Annan, E., K. Mustapha, S. T. Azeko, O. S. Odusanya, K. Malatesta, and W. O. Soboyejo. 2015. "Flow statistics and the scaling of ceramic water filters." Adv. Mater. Res. 1132: 267-283. https://doi.org/10.4028/www .scientific.net/AMR.1132.267.

ASTM. 2012. Standard test method for linear-elastic plane-strain fracture toughness KIc of metallic materials. ASTM E399. West Conshohocken, PA: ASTM.

ASTM. 2017. Standard test methods for flexural properties of unreinforced and reinforced plastics and electrical insulating materials. ASTM D790. West Conshohocken, PA: ASTM.
Bhatnagar, A., E. Kumar, and M. Sillanpää. 2011. "Fluoride removal from water by adsorption: A review." Chem. Eng. J. 171 (3): 811-840. https://doi.org/10.1016/j.cej.2011.05.028.

Bielefeldt, A. R., K. Kowalski, and R. S. Summers. 2009. "Bacterial treatment effectiveness of point-of-use ceramic water filters." Water Res. 43 (14): 3559-3565. https://doi.org/10.1016/j.watres.2009.04.047.

Brown, J., and M. D. Sobsey. 2009. "Ceramic media amended with metal oxide for the capture of viruses in drinking water." Environ. Technol. 30 (4): 379-391. https://doi.org/10.1080/09593330902753461.

Brown, J., and M. D. Sobsey. 2010. "Microbiological effectiveness of locally produced ceramic water filters for drinking water treatment in Cambodia." J. Water Health 8 (1): 1-10. https://doi.org/10.2166/wh .2009.007.

Clasen, T. F., J. Brown, S. Collin, O. Suntura, and S. Cairncross. 2004. "Reducing diarrhea through the use of household-based ceramic water filters: A randomized, controlled trial in rural Bolivia." Am. J. Trop. Med. Hyg. 70 (6): 651-657. https://doi.org/10.4269/ajtmh.2004.70 .651 .

De Leeuw, N. H. 2002. "Density functional theory calculations of local ordering of hydroxyl groups and fluoride ions in hydroxyapatite." Phys. Chem. Chem. Phys. 4 (15): 3865-3871. https://doi.org/10.1039 /b203114k.

Dixon, W. J., and F. J. Massey. 1951. Introduction to statistical analysis. New York: McGraw-Hill.

Donachy, B. 2011. Summaries of reports and studies of the ceramic water purifier (CWP): A colloidal silver (CS) impregnated ceramic water filter. Dodgeville, WI: Potters for Peace.

ICAITI (Central American Research Institute of Industrial Technology). 1984. Identification and evaluation of design alternatives for a low cost domestic filter for drinking water. Guatemala City: ICAITI.

Kropinski, A. M., A. Mazzocco, T. E. Waddell, E. Lingohr, and R. P. Johnson. 2009. "Enumeration of bacteriophages by double agar overlay plaque assay." In Vol. 501 of Bacteriophages: Methods in molecular biology, edited by M. R. Clokie, and A. M. Kropinski, 69-76. New York: Humana Press.

Lantagne, D. S. 2001a. Investigation of the Potters for Peace colloidal silver-impregnated ceramic filter: Field investigations. Allston, MA: Alethia Environmental.

Lantagne, D. S. 2001b. Investigation of the Potters for Peace colloidal silver-impregnated ceramic filter: Intrinsic effectiveness. Allston, MA: Alethia Environmental.

Michen, B., J. Fritsch, C. Aneziris, and T. Graule. 2013. "Improved virus removal in ceramic depth filters modified with MgO." Environ. Sci. Technol. 47 (3): 1526-1533. https://doi.org/10.1021/es303685a.

Michen, B., F. Meder, A. Rust, J. Fritsch, C. Aneziris, and T. Graule. 2012. "Virus removal in ceramic depth filters based on diatomaceous earth." Environ. Sci. Technol. 46 (2): 1170-1177. https://doi.org/10.1021 les2030565.

Nigay, P. M., A. Nzihou, C. E. White, and W. O. Soboyejo. 2017a. "Structure and properties of clay ceramics for thermal energy storage." J. Am. Ceram. Soc. 100 (10): 4748-4759. https://doi.org/10.1111/jace.15014.

Nigay, P. M., A. Nzihou, C. E. White, and W. O. Soboyejo. 2018. "Removal mechanisms of contaminants in ceramic water filters." J. Environ. Eng. 144 (12): 04018128. https://doi.org/10.1061/(ASCE)EE.1943-7870 .0001471 .

Nigay, P. M., A. A. Salifu, J. D. Obayemi, C. E. White, A. Nzihou, and W. O. Soboyejo. 2019. "Ceramic water filters for the removal of bacterial, chemical, and viral contaminants." J. Environ. Eng. 145 (10): 04019066. https://doi.org/10.1061/(ASCE)EE.1943-7870.0001579.

Nigay, P. M., R. Sani, T. Cutard, and A. Nzihou. 2017b. "Modeling of the thermal and mechanical properties of clay ceramics incorporating organic additives." Mater. Sci. Eng., A 708 (Dec): 375-382. https://doi .org/10.1016/j.msea.2017.09.131.

Oyanedel-Craver, V. A., and J. A. Smith. 2008. "Sustainable colloidalsilver-impregnated ceramic filter for point-of-use water treatment." Environ. Sci. Technol. 42 (3): 927-933. https://doi.org/10.1021/es071268u.

Plappally, A., I. Yakub, L. C. Brown, W. O. Soboyejo, and A. B. O. Soboyejo. 2011. "Physical properties of porous clay ceramic-ware." J. Eng. Mater. Technol. 133 (3): 031004-1-031004-9. https://doi.org/10 .1115/1.4004158. 
Potters for Peace. 2019. "Ceramic water filter project." Accessed March 24, 2019. https://pottersforpeace.org.

Sobsey, M. D., C. E. Stauber, L. M. Casanova, J. M. Brown, and M. A. Elliott. 2008. "Point of use household drinking water filtration: A practical, effective solution for providing sustained access to safe drinking water in the developing world." Environ. Sci. Technol. 42 (12): 4261-4267. https://doi.org/10.1021/es702746n.

Tsao, N. H., K. A. Malatesta, N. E. Anuku, and W. O. Soboyejo. 2016. "Virus filtration in porous iron (III) oxide doped ceramic water filters." Adv. Mater. Res. 1132: 284-294. https://doi.org/10.4028/www .scientific.net/AMR.1132.284.

USAID (United States Agency for International Development). 1998. Hurricane Mitch preliminary damage assessment report. Washington, DC: USAID.

van der Laan, H., D. van Halem, P. W. M. H. Smeets, A. I. A. Soppe, J. Kroesbergen, G. Wubbels, J. Nederstigt, I. Gensburger, and S. G. J. Heijman. 2014. "Bacteria and virus removal effectiveness of ceramic pot filters with different silver applications in a long term experiment."
Water Res. 51 (Mar): 47-54. https://doi.org/10.1016/j.watres.2013.11 .010 .

van Halem, D. 2006. "Ceramic silver impregnated pot filters for household drinking water treatment in developing countries." M.Sc. thesis, Dept. of Water Management, Delft Univ. of Technology.

Yakub, I., et al. 2013. "Porosity, flow, and filtration characteristics of frustum-shaped ceramic water filters." J. Environ. Eng. 139 (7): 986-994. https://doi.org/10.1061/(ASCE)EE.1943-7870.0000669.

Yakub, I., J. Du, and W. O. Soboyejo. 2012. "Mechanical properties, modeling and design of porous clay ceramics." Mater. Sci. Eng., A 558 (Dec): 21-29. https://doi.org/10.1016/j.msea.2012.07.038.

Yakub, I., and W. O. Soboyejo. 2012. "Adhesion of E. coli to silver or copper coated porous clay ceramic surfaces." J. Appl. Phys. 111 (12): 124324-1-124324-9. https://doi.org/10.1063/1.4722326.

Yakub, I., and W. O. Soboyejo. 2013. "Adsorption of fluoride from water using sintered clay-hydroxyapatite composites." J. Environ. Eng. 139 (7): 995-1003. https://doi.org/10.1061/(ASCE)EE.1943-7870 .0000692 . 